University, and chairman of the Center for European Studies. He is author of Duties Beyond Borders (1981), Dedine or Renewal: France Since the Thirties (1974), and Primacy or World Order (1978).

\section{Uncle Wuffle's Advice to the Advanced Graduate Student*}

A Wuffle

University of California, Irvine

1. In looking for a Ph.D. topic, there is only one rule; if you aren't excited about it, don't do it. The only person who can motivate you for the long grind that is a Ph.D. is you.

2. In writing a Ph.D., there is one nearguaranteed piece of good advice: write your literature review chapter last. l've seen numerous graduate students endlessly spin their wheeis trying to decide when they'd reviewed all the literature they needed to write their dissertation. Literature is endless; a graduate student's life is finite.

\section{.... if you aren't excited}

\section{about it, don't do it.}

After the dissertation is written, with hindsight, you'll see what literature actually was critical and how it influenced the questions you asked and the answers you came up with. However, this doesn't mean that you don't read and read and read before writing. There are no rewards in academic life for re-inventing the wheel.

3. Every scholar must steer a line between the Scylla of trying to hold onto work until it's perfect (which guarantees zero output) and the Charybdis of submitting work that ought not to see the light of day (which guarantees zero acceptances). Learning to do this steering isn't easy, and the best tutor is trial and error, and a lot of help from friends and faculty advisors.

4. An academic is known by the articles he/she writes; but it is better to have written and gotten into a minor journal than never to have gotten published at all. (However, also see rules $5,9,10$, and 11.$)$

5. One article in a major journal is worth two or more in a minor journal; hence, patience pays for an article that you really believe in. However, some articles belong in minor journals.

\section{Literature is endless; a}

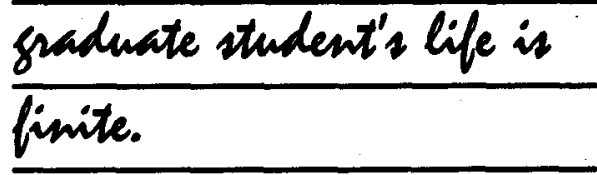

6. Take manageable bites. Section booklength work into chapters and chapters (articles) into sections, and write a chunk at a time. If you don't, you run the risk of being overwhelmed. Also, it's amazing how rapidly a page a day, say, mounts up.

7. At least when you're starting off, the single most important thing to do to increase the likelihood of writing a good research paper is to write a good outline.

8. In looking for research topics the question is, "What's the question?" If the question you are asking isn't an interesting one, it won't matter that yours is the definitive answer. Every empirically minded social scientist must steer the path between what is doable and what is really worth doing.

9. It is better to be the second author of a first-rate article than the first author of a second-rate one.

10. Articles are almost never accepted without further revisions, and only rarely accepted by the first journal to which you submit them (especially if it is a first-rate journal); hence, when at first you don't succeed, try and try and try again. 
11. Getting your dissertation done is extremely important. You're very unlikely to get a good job without a Ph.D. in hand. However, getting articles accepted for publication is also very important. Most of my colleagues advise you to convert the appropriate sections of your dissertation into articles only after the dissertation is finished. I think you should do so simultaneously, as you complete them. That way, not only do you get possible published articles but you also get valuable professional feedback.

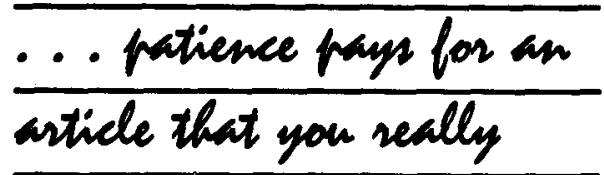

\section{believe in.}

12. The more people you show your work to, the more people there are who might read it. But all advice is not equal, and writing a thesis should not resemble a popularity/public opinion poll. Remember, it's your thesis.

13. Choose an advisor whom you respect both as an intellect and as a human being. (Not necessarily in that order.)

14. Before going on a job interview learn the names (and even read some of the articles) of the people who are going to interview you. There's nothing so embarrassing as being introduced to somebody with no idea who they are, when they think that everybody should know who they are and why they're "famous."

15. In going on a job interview, there is only one rule: Be yourself. When you are interviewing be warned, however, that many (if not most) of the faculty at the institution where you sent your vita and publications, didn't read them. Thus, reminding people of who you are and what you do can't hurt.

\section{Notes}

* I am indebted to jim Danziger for helpful comments, also the original idea for item $\mathrm{fl}$ | was his. Items $/ 12$ and $f 13$ were added by Kristen Monroe as was a portion of item / 15. However, the views expressed in this essay are solely the responsibility of the author.

\section{Congressional and Presidential Scholars: Some Basic Traits*}

\author{
Christopher J. Bosso \\ Northeastern University
}

\section{Introduction}

Accustomed as we students of American politics are to training our analytical tools on various segments of the national population, we rarely use them on ourselves. Perhaps we are not all that interested in knowing more about who we are, either as people or as scholars. Perhaps the academic reward system finds little worth in such studies. Perhaps we really do not want to know whether there exist any noticeable biases among those whose scholarship and teaching influence generations of students and politicians.

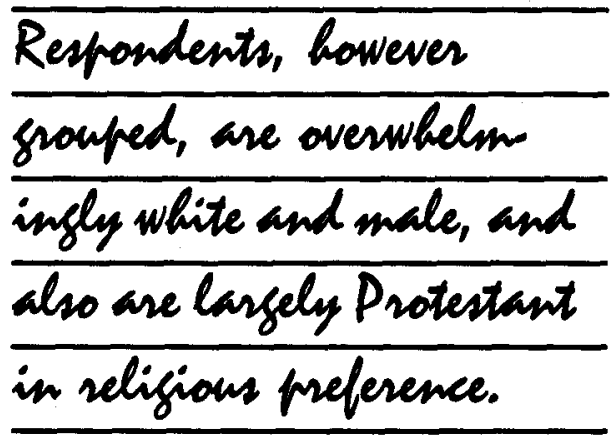

Whatever is the case, and it might well be a mixture of all three reasons, the purpose of this essay is to present summary data on some basic personal and professional traits of two scholarly cohorts within 